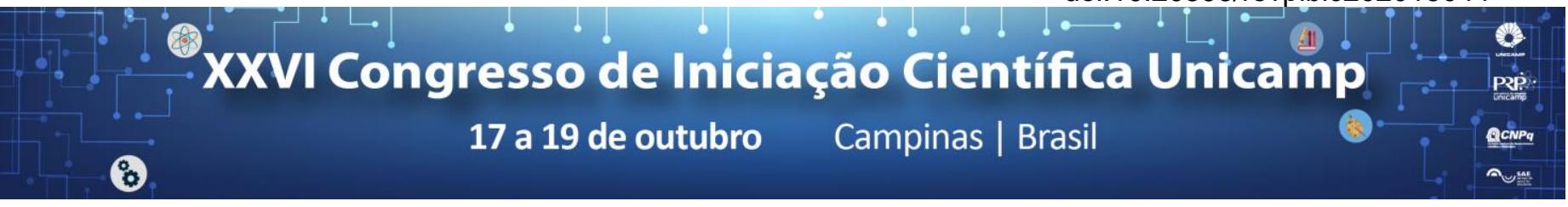

\title{
Análise das variáveis baropodométricas, a partir do uso da plataforma de força
}

\section{Jacqueline R. Morandin*, Lucas A. Monezi, José Adolfo D. Nabas, Luciano A. Mercadante.}

\section{Resumo}

Em busca por melhores condições de vida, evitando problemas locomotores, muitas vezes acometidos devido a questões posturais, são realizados inúmeros estudos relativos à baropodometria, a qual auxilia nos diagnósticos de problemas da distribuição da pressão plantar, responsável por inúmeras patologias posturais. Entre as variáveis obtidas nestes estudos está a curva da força de reação do solo em função do tempo, obtida a partir do protocolo de marcha, aplicando repetições do ciclo da marcha. Esse trabalho discute, portanto, a estabilidade das curvas médias da força de reação do solo em função do número de repetições do ciclo.

\section{Palavras-chave:}

baropodometria, baropodômetro, força de reação do solo.

\section{Introdução}

Pesquisas acerca dos mecanismos de controle postural objetivando melhores condições de vida (BANKOFF et al., 2004) podem ser realizadas através das medidas da pressão plantar e da força de reação do solo na planta do pé, método de análise conhecido como baropodometria (DUARTE; FREITAS, 2010). A análise é estabelecida a partir do uso de um equipamento conhecido como baropodômetro, uma plataforma eletrônica, a qual detecta a força aplicada pelo corpo sobre ela por meio dos sensores dispostos ao longo da mesma (BARELA; DUARTE, 2011).

Durante a realização do protocolo de marcha na esteira do baropodômetro, cada ciclo completo pode ser estudado, possibilitando a interpretação da forma pela qual o indivíduo troca forças com o solo durante 0 movimento. Desse modo, o presente estudo visa discutir o número necessário de repetições do ciclo de marcha para que os valores médios da força de reação do solo se estabilizem.

\section{Resultados e Discussão}

Para a análise foi utilizado o baropodômetro do modelo FootWork® Pro Walk XXL, marca Amcube, foram realizados seis protocolos consecutivos, totalizando a realização de 53 e 55 ciclos da apoio, respectivamente esquerdos e direitos. Foram excluídos os dados errôneos fornecidos pelo programa associado ao baropodômetro. A exclusão deu-se através da análise comparativa das imagens obtidas pelo sistema do equipamento com as fornecidas pelo software desenvolvido para análise das curvas de força de reação do solo, já normalizadas pelo sistema, a fim de viabilizar a comparação entre as curvas.

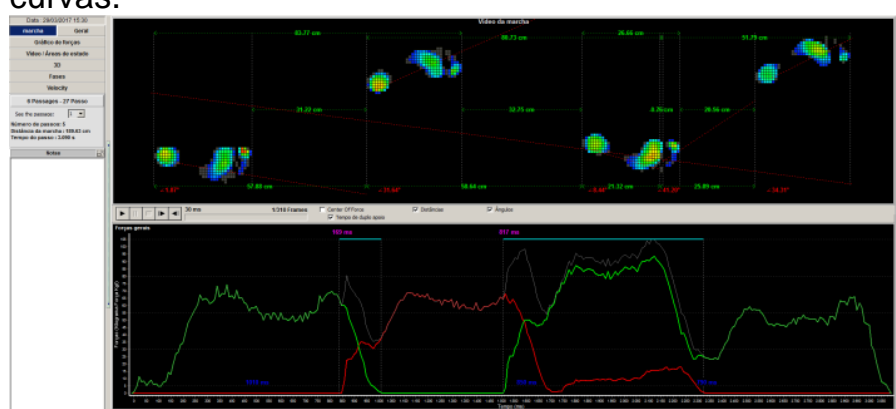

Figura 1. Exemplo da pressão plantar (acima) e da curva da força de reação do solo (abaixo), uma passagem durante a realização do protocolo de marcha. Fonte: print screen do programa Footwork Pro 3.8.1.1 associado ao baropodômetro.

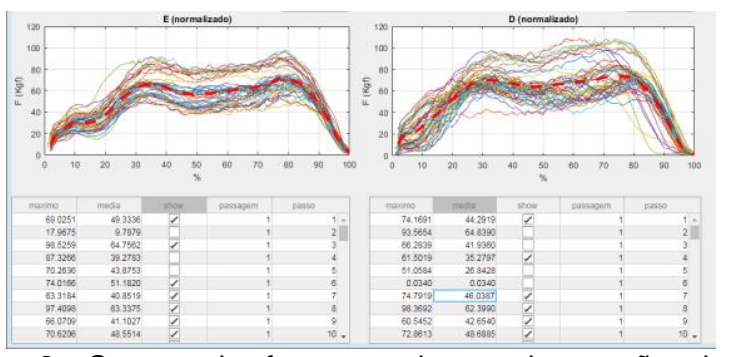

Figura 2. Curvas da força resultante de reação do solo normalizada pelo ciclo da passada (0-100\%). Destaque para a linha tracejada vermelha da curva média calculada ponto a ponto, para os ciclos de apoio, esquerdo (E) e direito (D), respectivamente.

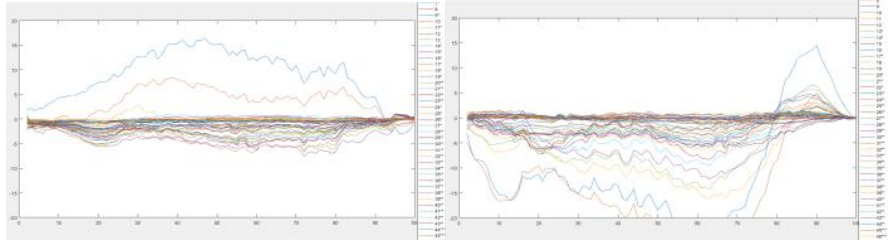

Figura 3. Estabilização do cálculo da curva média força dos passos realizados com 0 apoio esquerdo e direito, respectivamente. Curvas dos erros médios da força de reação do solo, calculadas com incremento de uma passada.

\section{Conclusões}

Após o décimo quinto ciclo, considerando os valores para cada lado, esquerdo e direito, o erro máximo na curva de força foi sempre menor que $10 \%$. Fundamentado a isso, é importante considerarmos o mínimo de duas realizações do protocolo, com 24 passos de cada pé, direito e esquerdo, ou seja, 24 passadas totais, para se alcançar resultados mais fidedignos, com a ME de pelo menos $10 \%$.

\section{Agradecimentos}

Ao programa CNPq/PIBIC pelo financiamento do projeto de pesquisa e a Clínica Núcleo de Ortopedia, Medicina Esportiva e Reabilitação Ltda. que possibilitou a realização da pesquisa dispondo o equipamento utilizado.

Bankoff, A., Ciol, P., Zamai, C., Schmidt, A., \& Barros, D. (n.d.). Estudo do equilíbrio corporal postural através do sistema de baropodometria eletrônica.

Barela, A., \& Duarte, M. Utilização da plataforma de força para aquisição de dados cinéticos durante a marcha humana. Brazilian Journal of Motor Behavior, v.6, p.56-61, 2011.

Duarte, M., \& Freitas, S. M. Revision of posturography based on force plate for balance evaluation. Revista Brasileira de Fisioterapia, v. 14, p.183-192, 2010 